\title{
CARTA ABIERTA A HANS CHRISTIAN ANDERSEN EN EL BICENTENARIO DE SU NACIMIENTO
}

\section{Resumen}

El 2 de abril del 2005 se realizó una doble celebración: el bicentenario del natalicio del escritor danés Hans Christian Andersen y el Día Internacional del Libro Infantil. Se considera a este autor como el creador de la literatura para niños contemporánea, por introducir discursos reservados, hasta aquel momento, exclusivamente para adultos.

La "Carta abierta" fue leída a estudiantes de la Universidad Centroamericana (UCA) en Managua, Nicaragua, en el marco del Festival dedicado a Andersen, organizado por la Fundación Libros para Niños con el apoyo de las embajadas de Noruega y Dinamarca. En ella, se trata de establecer un perfil biográfico de Andersen y se exploran posibles lecturas de sus cuentos, desde perspectivas educativas, psicológicas y psicoanalíticas. Concluye con una interpretación de Andersen como metáfora del entendimiento y el diálogo entre Costa Rica y Nicaragua.

Asimismo, este trabajo es la base para el suplemento Educare en el aula, el cual contiene ideas para la motivación a la lectura. Como complemento, se adiciona el cuento El porquerizo de Hans Christian Andersen.

\section{Abstract}

April $2^{\text {nd }}, 2005$ was a day for a double celebration: the bicentennial of the birth of Danish writer Hans Christian Andersen and the International Children's Book Day. Andersen is known as the creator of contemporary children literature, for his fairy tales introduce language that at that time was used by adults only.

Students from Central American University (UCA) in Managua, Nicaragua, read an "Open Letter" during a Festival that the Books for Children Foundation

\footnotetext{
${ }^{1}$ Carlos Rubio Torres: Profesor e investigador de literatura infantil. Labora en la División de Educación Básica y en la División de Educación Rural del CIDE, UNA, así como en la Escuela de Formación Docente de la UCR. Autor de La vida entre los labios (poesía, 1985). Queremos jugar (cuento, 1990). Pedro y su teatrino maravilloso (cuento, 1993), Escuela de hechicería, matrícula abierta (novela, 1996), El libro de la Navidad (cuento, 2001) y La mujer que se sabía todos los cuentos (cuento, 2003). Su sitio en la Internet es www.carlosrubioescritor.com
} 
organized in honor of the author along with the Norwegian and Danish embassies. The letter presents Andersen's biography and explores alternative readings of his fairy tales from educational, psychological and psychoanalytical perspectives. The letter concludes with an interpretation of Ander- sen as a metaphor for the understanding and dialogue between Costa Rica and Nicaragua.

Descriptores: literatura infantil, niños, lectura, libro, educación.

Estimado señor Andersen:

$\mathrm{U}$ sted es, indiscutiblemente, el príncipe de los cuentos de hadas. Pero también es el viajero incansable que describió todo lo que vio en libros; fue destacado novelista, ingenioso al recortar figuras de papel, dramaturgo no tan afortunado y hombre misterioso en su inquietante soledad. Permítame unos minutos su atención, señor Andersen, y espero que no lo moleste si lo llamo, al igual que muchos, "el cisne de Dinamarca". Sé que hay discusiones que aún hoy lo abruman; hay quien, a inicios del siglo XXI, sostiene que un hombre con una vida como la suya —que usted tanto se esforzó en hermosear en autobiografías - no haya escrito los más apropiados textos para las jóvenes generaciones. Lo cierto es que sus cuentos son leídos en más de cien idiomas a lo largo y ancho del mundo y, el día de su nacimiento, que hoy festejamos, es también el Día Internacional del Libro Infantil. Reciba por favor, a manera de un regalo de cumpleaños, esta carta escrita en Centroamérica.

Contrario a lo que sus lectores puedan imaginarse, don Hans, usted tuvo pocos libros en su infancia. Tal como lo refiriera en su propia autobiografía, $E l$ cuento de mi vida (1989), le tocó vivir en un ambiente hostil para un muchacho que se convertiría, con el paso del tiempo, en uno de los escritores más destacados de Dinamarca. Nació el 2 de abril de 1805 en Odense, la principal ciudad de la isla de Fionia. Edmée Álvarez (1986) nos dice que su madre, Marie Andersdatter, fue una humilde lavandera, y que no sabía escribir y que, con costos, leía. Aún era una niña, cuando la obligaban a pedir limosnas por las calles. Muerta de vergüenza, no sabía cómo regresar a la casa con las manos vacías. ¿Puedo preguntarle... se parecía su madre a la vendedora de fósforos que tirita de frío en la noche de Navidad? Cubero (1987) nos cuenta que su mamá, al contraer nupcias con su padre, ya llevaba consigo una hija que había tenido con un alfarero casado. Muy diferente a lo ocurrido a la dulce vendedora de fósforos, cuya abuela bajó del cielo para llevarla por un camino glorioso de resplandores, su madre falleció en la miseria, alcoholizada, en un asilo de su ciudad 
natal, cuando usted tenía veintiocho años, viajaba por Nápoles y empezaba a ganar notoriedad como escritor. Su hermana mayor, afirma Montes (2001) terminó prostituyéndose y me parece que a usted no le gusta referirse a ella. Su abuelo sufría trastornos mentales: recorría las calles de Odense coronado con flores, vestido estrafalariamente, cambiando sus raras tallas en madera por jamones. Su abuela trabajaba como jardinera en el manicomio y sabía contar cuentos. Y ese acto marcó su vida y, a la larga, hizo que usted pudiera sobrevivir a una infancia desoladora. El poder misterioso e inexorable de los cuentos le dieron la suficiente fuerza para imponerse a un destino insignificante.

¿Lo recuerda? Usted era un niño y escuchaba historias maravillosas de labios de su abuela y de su padre, Hans Andersen, zapatero remendón, de temperamento libre que nunca quiso agremiarse y que tuvo aspiraciones de enrolarse en el ejército y alcanzar el grado de teniente; férreo admirador de Napoleón, se alistó en uno de los batallones que marchaba a Rusia. Regresó a casa sin haber participado en una sola batalla y falleció — según Bonning (1996)-, cuando usted apenas había alcanzado los once años. Pero aquí, al lado suyo, recordamos a ese zapatero que le leía. Su papá destinaba ratos libres para leerle, en voz alta, fragmentos de La Fontaine, Holberg (considerado el padre del teatro danés) y cuentos de Las mil y una noches. Le dejó, como herencia, un teatro de títeres que él mismo construyó. Y usted lleva aún ese teatro consigo. Bien sé lo que ama los escenarios y desea, con pasión, convertirse en dramaturgo, cantante, bailarín o actor.

Pero pocas eran las posibilidades que usted tenía, muchacho rural y proletario, para convertirse en artista. Su madre insistía en que debía aprender el oficio de sastre. Y ante su resistencia, consultó su futuro a una adivina. Edmée Álvarez (1986) recreó su respuesta:

—Tu hijo será un gran hombre - le dijo—y algún día llegará a ser el orgullo de la patria. Deja que emprenda el viaje a la capital y habrás cumplido con el mejor de los deberes.

Y así fue, usted contaba con tan sólo catorce años, cuando su madre le permitió que se marchara a Copenhague con el firme propósito de transformarse en una personalidad del Teatro Real de la capital. En plena adolescencia, y al igual que el patito feo, sufrió desengaños y humillaciones. De nada le sirvió la carta de recomendación que llevaba para Madame Schall, una consagrada bailarina. Montes (2001) y Edmée Álvarez (1986) coinciden en que esta mujer lo echó de su casa sin miramientos. Y es que esa figura de muchacho pobre, con una educación deficiente, no le ayudaba en nada.

Desmesuradamente alto, inseguro, torpe, mal vestido y con los zapatos repletos de barro. ¿Quién iba a tenerle fe? Giussepi Siboni, tenor italiano y 
director del Teatro-Escuela de Música, empezó a ayudarlo con algún dinero y a ofrecerle lecciones de canto. Mas, mala suerte la suya; el invierno de 1822 fue demasiado crudo. Usted, novel cantante, soportó el hielo con mala alimentación, sin cuidados y falto de ropa caliente. Como resultado, echó a perder su garganta. Edmée Álvarez (1986) nos dice que el médico diagnosticó que ya nunca podría cantar (al igual que la Sirenita, cuya lengua fue cortada por la malvada Bruja del Mar). No le quedó más remedio que acudir donde otro mecenas. Se trataba del consejero de Estado Jonás Collin, quien lo adoptó como a un hijo. Lo envió a un colegio para que terminara su bachillerato. Tan mala era su educación que, con 17 años, tuvo que prepararse al lado de estudiantes de 12 y 13. ¿Cómo resistía las burlas?; sin embargo, logró presentar sus exámenes al cumplir los 23, con el apoyo de clases particulares. Durante esos años, leyó con pasión a Shakespeare y a Walter Scott. Y tuvo claridad sobre su vocación, aunque el latín le resultara difícil, usted, señor Andersen, se convertiría en escritor.

Su primera novela, El improvisador, publicada en 1835, le deparó fama y dinero. Se trataba de un texto autobiográfico que se publicó, con una inmediatez sorprendente en sueco, ruso, holandés, francés, checo, polaco, alemán e inglés, según nos dice Cubero (1987). Ese mismo año, dio a conocer una obra que usted, en un principio, consideró menor. Se trataba de un cuaderno, con cuatro breves historias, titulado Cuentos de hadas para niños, que incluía, tal como lo expresa el índice comentado de la Editorial Gaviota (1987), los siguientes textos: El mechero, Nicolasín y Nicolasón, La princesa y el guisante y Las flores de la pequeña Ida. $\mathrm{Al}$ parecer, su único interés era el de revivir el placer de escuchar los relatos que su padre le contó en la infancia. Los críticos consideraron que sus cuentos eran perfectos y que cada uno de ellos "tenía la esencia de un poema". Tal fue el éxito, que no dudó en publicar otros cuadernos que se propagaron por Dinamarca, Suecia, Alemania e Inglaterra. Se dijo que en la literatura danesa había aparecido una nueva prosa, que el idioma se transformaba y adquiría la gracia y la frescura de la sencillez.

A los 30 años, dejaba de ser aquel muchacho al que le cerraron las puertas en las narices y empezaba a convertirse en el más traducido y reconocido de los escritores de su patria. Tanto así, que el rey Federico VI le proporcionó una pensión real, suficiente para que pudiera vivir en forma digna. Esta holgura económica le permitió crear una cadena de historias. Hoy en día, la "lista oficial" incluye 156 cuentos escritos hasta 1872, tal como lo expone el artículo Hans Christian Andersen, su pequeña y larga historia en fechas, de la Revista Informaciones Danesas, editada por el Recll Ministerio de Asuntos Exteriores de Dinamarca y publicada como prólogo de Cuentos de hadas para niños II (1985). 
Pero, ¿qué de mágico y misterioso hay en sus cuentos? ¿Qué nos hace leerlos con esa pasión casi religiosa? En un principio, usted elaboraba relatos fundamentados en el folclore escandinavo - tal como lo hacían los hermanos Grimm en Alemania-. Fueron muchos los antecesores que tenía. Como lo dice Pascual (1997), Charles Perrault había dado a conocer en la Francia de 1697, un libro llamado Cuentos de antaño con sus moralejas. Por los pasillos de Versalles y, con un posible cuchicheo en los oídos del propio Luis XIV, el "Rey Sol", se decía que Perrault, aquel abogado y no muy lucido miembro de la Academia Francesa, había recreado

\section{Los críticos consideraron}

que sus cuentos eran

perfectos y que cada uno de ellos "tenía la esencia de un poema". Tal fue el éxito, que no dudó en publicar otros

cuadernos que se

propagaron por Dinamarca, Suecia, Alemania e Inglaterra. Se dijo que en la literatura danesa habia aparecido una nueva prosa, que el idioma se

transformaba y adquiría la gracia y la frescura de la sencillez. cuentos que campesinas y abuelas iletradas narraban a los más pequeños. Se trataba de Cenicienta o el zapatito de cristal, La Bella Durmiente del Bosque, Pulgarcito o Caperucita roja. Cincuenta años después, Madame Leprince de Beaumont, una disciplinada institutriz francesa, incluía en un libro pedagógico llamado Bazar de los niños, el relato de La Bella y la Bestia, posiblemente inspirada en el antiguo mito griego de Eros y Psique, como lo sugiere Marín (1992). Y en forma casi simultánea a usted, los prolijos hermanos Jacob y Wilhelm Grimm, se dieron a la tarea de recorrer la ciudad de Kassel y otras regiones de Alemania recopilando cuentos. Seijo Castroviejo (1996) afirma que estos hermanos llegaron a recoger 201 cuentos y 10 leyendas, que incluyeron nuevas ver-

siones de Cenicienta o Caperucita roja, así como textos no muy conocidos en el mundo académico de aquel entonces: Blancanieves, Rapunzel o Juan y las habichuelas mágicas.

Pero usted, señor Andersen, se diferenció de todos ellos por una razón muy especial: se guió por su propia fantasía y no se apegó a lo que dictaba el texto vernáculo. A usted no le interesó hacer una recopilación del folclore de su país y ponerla en manos de los niños. Por el contrario, llegó a crear breves novelas como El ruiseñor, El abeto y La reina de la nieve, en las que los personajes imaginados adquirieron una notable profundidad psicológica. "Concibo 
una idea para adultos -expresó usted en su autobiografía El cuento de mi vida (1989) - y la escribió para que la entiendan los niños, pues a menudo pienso que los padres escuchan, ya que es conveniente que tengan entretenido su pensamiento". Será por eso que usted está presente en todos sus cuentos. Usted es el patito feo que alza las alas hacia horizontes de luz y belleza. También es la Sirenita, ajena a un mundo terrenal, sin voz propia. Es el niño que grita en plena calle "El rey no tiene nada puesto". No en vano, y aunque esto lo haga sonreír, Hans Brix (citado por la Revista Informaciones Danesas, 1985) expresó: “Andersen se ha retratado más veces a sí mismo en sus obras, que autorretratos llegó a pintar Rembrandt".

Aún así, fue reticente a que le tomaran fotografías. Desde muy joven era consciente de su cuerpo: demasiado alto, con pies y manos desmesuradamente grandes, nariz ancha y larga y ojos diminutos. Informaciones Danesas, (1985) cuenta que usted enfureció cuando Ludvig Phister, en una velada, le expresó:

- Señor Andersen, de joven, no era bien parecido, pero que con el paso de los años, su rostro ha adquirido un raro encanto, un extraño atractivo.

—Bien sé que soy más feo que guapo, —le respondió- pero debería respetar en mí aquello que es digno de ser respetado y no reírse de mí en mi cara. Ahora me ha destrozado usted la velada. Muchísimas gracias. Ahora me voy a mi casa.

Pocos amores a usted se le conocen. Pocos amores no correspondidos. Discúlpeme, sé que hablar de esto lo perturba, pero también sé cuánto de esos amores aparecen en sus cuentos. Por eso, le recuerdo su admiración por los ojos castaños de la joven Riborg Voight. Usted quiso ver más de cerca la mirada azul de Louise Collin, hija de su protector. Mucho lo fascinó el canto de Jenny Lind, a quien presentaban en los escenarios como el "ruiseñor de Suecia" y a pesar de que usted le dedicó el cuento "El ruiseñor", ella sólo le devolvió la fraternidad de una hermana. Todas estas mujeres se casaron con otros, tal como lo expresa Soriano (1995) y muchos otros investigadores. La revista electrónica Imaginaria (2000, consultada el 22 de marzo del 2005) se refiere a su presunta homosexualidad, la cual nunca ha sido reconocida por los especialistas daneses. Su biógrafa Wullschlager establece un análisis comparativo entre la autoinmolación de la Sirenita enamorada del príncipe y las cartas que, en forma simultánea a la composición del cuento, usted le escribía a Edvard, hijo de su protector y mecenas, Jonas Collin. Sin embargo, él también se casó. Se casaron sus amigos y usted continuaba allí, en la ventana de su habitación, contemplando los faroles de las calles de Copenhague. Gracias a esa inmensa tristeza y su irresoluta soledad, los niños saben que los finales no siempre son felices y que el amor puede trascender las puertas de la muerte, como el amor del soldadito de plomo 
y la bailarina, que se funden en el fuego infinito de una estufa. De él sólo quedan cenizas y de ella, una lentejuela negra como el carbón.

Definitivamente, como lo dice Edmée Álvarez (1986), tuvo a su favor que corrieran los vientos del romanticismo sobre Dinamarca. El siglo anterior había sido una época de reglas clásicas y allí un alma como la suya no hubiera tenido cabida. Los románticos de su tiempo se opusieron, en forma decidida, a La Poética de Aristóteles y a los preceptos de los latinos y decidieron darle rienda suelta a la ruptura de las normas establecidas, al sentimentalismo y al dominio del corazón sobre el cerebro. Usted supo del romanticismo francés y no en vano visitó, personalmente, a Víctor Hugo en París. También supo de un romántico alemán, Klopstock, que llevó el influjo del idealismo, la exaltación de la nobleza y la libertad de espíritu a los artistas e intelectuales daneses. Debemos recordar que los románticos valoraron la poesía primigenia por encima de la poesía académica, tal como lo señala el estudio de Ruzicka Kenfel (1996). Es decir, la poesía primigenia era aquella que estaba en boca del pueblo, libre de la contaminación de las normas establecidas por teóricos y el deseo por parecerse a los antiguos griegos y romanos. Así que sus relatos, contados con la sencillez y la belleza de quien sabe dialogar con el pueblo, fueron leídos con atención en Europa y América.

Ahora que digo América, y me imagino que este recuerdo le borrará cualquier angustia, Edmée Álvarez (1986) expresa que, entre los muchos reconocimientos y homenajes que recibió en vida, el gobierno de México le otorgó la Orden de Guadalupe el 25 de abril de 1866. Así usted supo que también lo admirábamos en América Latina.

Tal como lo dice Montes (2001), con usted nació un cuento nuevo. Los antiguos cuentos de hadas, que su padre le contaba, son típicos: las imágenes son medulares. Digamos junto con el antropólogo literario Vladimir Propp (1987) que las funciones características de los protagonistas no varían. Hay una severísima economía en el relato y todo está al servicio del tiempo narrado. Todos los nombres son genéricos: el bosque en que se pierde Blancanieves puede tener las mismas características del bosque por donde deambulan Hänsel y Grettel. La bruja Baba Yaga, que atrapa dentro de su casa a Basilisa la hermosa, puede ser tan mala y perversa como la bruja que encierra a Rapunzel en lo alto de una torre. Podríamos decir, junto con Montes, que en el cuento de hadas "todo es arquetípico: la casa es todas las casas; el lobo, todos los lobos; el bosque, todos los bosques" (p. 109).

En cambio en sus cuentos, señor Andersen, los protagonistas y los objetos se convierten en seres reales y particulares. Sus descripciones son precisas y nos cuesta mucho diferenciar, si lo quisiéramos, dónde está "lo real" y donde 
está "lo fantástico". Siempre me ha maravillado el párrafo con que usted (Andersen, 1987, p. 111) inicia La Sirenita:

En alta mar el agua es azul como pétalos de bellísimos lirios y transparente como cristal purísimo, pero es tan profunda, que no hay ancla que pueda tocar fondo, y habrian sido necesarias numerosas torres de iglesias unidas para salvar la distancia entre el fondo y la superficie. Allí abajo vive la gente del mar:

Cómo admiro, don Hans, la forma en que usted transita, tal cual se tratara de una cuerda floja, entre la poesía y la precisión científica. Tal vez esto lo haya logrado, porque era un minucioso observador de la naturaleza. Tal vez sea porque, al contrario de lo que podamos imaginarnos, no sólo pasaba pendiente de la poesía; también se maravillaba con los avances tecnológicos de su tiempo. Edmée Álvarez (1986) dice que usted admiró el barco de vapor, el submarino "construido de forma perfecta", los faroles de gas y el daguerrotipo.

El mal dejó de ser el mal siempre concreto y visualizable de los cuentos de hadas. La bruja que quiere acabar con la belleza de Blancanieves o el lobo que devora a Caperucita son temibles, feos y hacen lo posible por destruir y anular a los héroes. Montes (2001) nos dice que usted trajo consigo dos formas de referirse al mal. Está el mal estético formado por espectáculos morbosos y escalofriantes. Así, la Bruja del Mar ha construido su palacio con huesos humanos y permite que dos culebras se enrosquen en tomo a sus enormes senos caídos (Andersen, 1987). Por otro lado, está el mal ético, que es el que está en la "naturaleza de las cosas". Es el de los mundos paralelos, el que está en injusticia, en la incomunicación, el de la muerte. Lo que pasa es que el héroe no puede hacer mucho para vencer al mal ético. La Sirenita sabe que no logrará conquistar el amor del príncipe, aunque le hunda el cuchillo en el pecho. Por eso, le besa la frente y arroja el arma a las olas. La muerte parece ser la única forma de sobrellevar el sufrimiento. Ese mal está en la naturaleza de las cosas y nadie puede cambiarlo.

Posiblemente, por eso, muchos teóricos y estudiosos han considerado inconvenientes, lascivos y demasiado crueles algunos de sus cuentos. Pardo Belgrano y Nervi (1979), señalan que "la crueldad de algunos de sus cuentos exige una rigurosa selección".

El conocido estudioso francés, Marc Soriano (1995, p. 79) señala:

Tal vez podamos hacer simplemente esto: reservar algunos cuentos como El niño en la tumba, por ejemplo, o Los zapatos rojos, u otros de igual 
tenor, para una edad que no sea de consumación inmediata, para un público sensible a su poesía, pero que sea capaz de defenderse del encanto maléfico que destilan.

El pedagogo italiano Nobile (1992), fundamentado en las ideas de Makarenko, señala que no toda su obra es adecuada para la infancia, pues algunos de sus cuentos no concluyen con un acto de moral reparadora y carecen de optimismo, esperanza, victoria, denuncia y cambio. Además, contienen una visión infeliz y a veces trágica del amor. Vea usted lo que hace el señor Nobile: trata de ubicar sus cuentos dentro de los estadios de desarrollo piagetiano. Y resulta que usted hizo una literatura que no concuerda con los principios epistemológicos propuestos por Piaget. Usted hace hablar objetos, lo cual es muy adecuado para niñas y niños de un estadio de desarrollo preoperacional, pero son textos tan complejos, que difícilmente pueden interesar a estos pequeños de dos a siete años. Por el contrario, esos mismos cuentos pueden resultar pueriles e ingenuos para niños más grandes. Ese es el problema, señor Andersen, de tratar de medir textos literarios con la misma vara con que se miden textos didácticos. Parece que se les olvida que usted nunca fue terapeuta ni pedagogo. Usted fue un artista, un artista consumado.

El psicoanalista de las hadas, Bruno Bettelheim (1990), considera que cuentos como La niña de los fósforos o El patito feo no sirven para la identificación de niños pequeños, pues no transmiten, al final, ese consuelo característico de los cuentos de hadas. Los protagonistas no muestran convicciones para escapar de su propio destino.

Una de las lecturas más recientes de sus cuentos es la que hace el psicólogo Cashdan (2000). Tal como lo establece en el título de su estudio, La bruja debe morir, él cree que las temidas hechiceras habitan dentro de nosotros y nos impiden alcanzar las más ansiadas realizaciones. La Bruja del Mar, que aparece en La Sirenita, representa la temprana y permisiva vivencia de la sexualidad. Precisamente, en la versión cinematográfica de Disney, Úrsula, la bruja marina, es caracterizada como un íncubo sobresexuado: pechos gigantescos, ojos lascivos, cejas arqueadas, labios sensuales, que canta al ritmo de música de cabaret; ella es, en palabras del propio Cashdan, un "útero suelto". Por su parte, la Sirenita no atiende las razones de su abuela, que la invita a esperar a que sea mayor para explorar el mundo terrenal, el que está más allá de la superficie del océano. La abuela es la antítesis de la bruja del mar: es el control de los impulsos. Así que, enamorada del príncipe, visita a la hechicera, entra en un territorio que es metáfora de los deseos sexuales desmedidos. Precisamente, la bruja la provee no sólo de dos piernas, sino del sexo que se encuentra en medio de ellas. 
Y así, sin haberse preparado adecuadamente, la Sirenita se lanza a la aventura de enamorar a un hombre. Para Cashdan, ella es símbolo de la lujuria, del deseo sexual prematuro. Los lectores saben en qué termina la historia: la agobiada sirena no logra encantar a su amado y es condenada a convertirse en espuma salada. Usted no se atreve a dejar a su protagonista en tan lamentable estado, por lo que nos dice que Dios la transforma en una hija del aire. Así, vagará por trescientos años llevando viento fresco por los países cálidos y tendrá, al finalizar ese período, un alma inmortal y dos ansiadas piernas. De esta forma, la niña y el niño saben que no deben precipitar los procesos de desarrollo de la sexualidad. Que dar rienda suelta a los deseos — sin estar preparado para ello- conduce a nefastos desenlaces.

Como ya lo habrá notado, fueron muchos los especialistas del siglo XX (psicólogos, psicoanalistas o pedagogos), que buscaron lo funcional o útil de sus escritos. Cuando descubrieron que algunos de ellos no sirven para terapias o aprendizajes, optaron por recomendarlos a muchachos más grandes o excluirlos, tajantemente, del canon de lo que puede considerarse como "literatura infantil".

Nos queda preguntarnos, ¿cómo leemos sus cuentos en esta región de América Latina? ¿Maravillarán a los niños del siglo XXI? Tengo la convicción, don Hans, de que usted seguirá siendo leído como hasta ahora. Es más, hoy más que nunca sus cuentos son presagios de un nuevo futuro.

Vengo de un país donde a diario llegan inmigrantes en busca de dignas condiciones de vida. En su gran mayoría, son personas trabajadoras, dispuestas a luchar por superar la brecha de pobreza. Al igual que usted apareció en Copenhague, con un atado de ropa y los ojos repletos de esperanza, son gentes que aspiran a traspasar los umbrales de ese Teatro Real que es el sueño más humano que puede tener cada uno de nosotros. En el escenario de ese teatro, está un futuro donde se respeta la integridad de hombres y mujeres. Sin embargo, tal como lo señala Sandoval (2003) en su libro Otros amenazantes. Los nicaragüenses y la formación de identidades nacionales en Costa Rica, muchos de mis compatriotas responden con discursos racializados, xenófobos y violentos. La prensa nacional destaca las acciones nefastas de unos pocos e invisibiliza la contribución que los inmigrantes están haciendo a la economía de mi país. Construimos nuestra propia identidad diferenciándonos del "otro". Se rechaza a algunos extranjeros (principalmente, si estos no son norteamericanos o europeos), porque se le consideran "otros" y se les excluye de los discursos oficiales con que se suele identificar la nación. Usted, don Hans, sabe muy bien eso, porque soportó el escarnio de ser "otro" en los salones donde se reunían artistas e intelectuales de Copenhague. El patito feo también es el "otro" que es rechazado 
por su madre y sus hermanos sencillamente por el hecho de ser distinto. La Sirenita es el "otro", que al igual que muchos inmigrantes, debe permanecer callada, porque les han cortado la lengua y han quedado sin voz propia. Aunque camine y baile con inigualable gracia, a quién le importa que ella sienta navajas por debajo de sus hermosos pies. Pienso, entonces, en miles de servidoras domésticas, constructores, agentes de seguridad, zafreros y campesinos que son contratados en términos ilegales y nadie les pregunta si sienten, como la Sirenita, el filo del dolor sobre su cuerpo. Los "otros" son los niños de La Carpio, quienes no tienen una escuela cómoda, un parque de juegos o una biblioteca para recrearse sanamente. Cientos de casas enfiladas una tras otra, que contienen cientos de historias de una otredad silenciada en Costa Rica. Así las cosas, qué falta nos hace que las jóvenes generaciones de nuestras patrias lean con atención estos cuentos de hoy de siempre y descubran el valor del entendimiento, la tolerancia y la solidaridad.

Tal como se habrá dado cuenta por medio de los periódicos, vivimos en países donde algunos exgobernantes se encuentran bajo llave, acusados de corrupción. Al igual que el vanidoso emperador, ellos se preocuparon obsesivamente por sus propias vestimentas. Lo que pasa es que los emperadores de hoy tienen cuentas electrónicas, hacen complejas transacciones bancarias, se hospedan en hoteles V.I.P. y viajan en vuelos privados para observar de cerca las pasarelas de Miami y París. Hace unos meses miraba pasar un camión de la policía por la calle, allí llevaban a un político, ahora convertido en privado de libertad. En ese momento, yo le preguntaba a usted cuántos de nosotros tendremos la valentía y la inteligencia del niño de su cuento para gritar: "El emperador no lleva puesto nada". Sí, no temeremos a que nos digan que somos estúpidos o que no estamos preparados para nuestro cargo. Diremos, con la claridad de un niño, "el emperador va desnudo, no lleva puesto nada".

Querido don Hans Christian, usted se fue de este mundo un 4 de agosto de 1875. Apenas tuvo fuerzas para asistir a los festejos oficiales que se celebraron en su 70 cumpleaños. Las ciudades de Odense y Copenhague estaban iluminadas en su honor y los niños desfilaron frente a usted, pletóricos de guimaldas de flores, anunciando tiempos nuevos. Nos dejó novelas, libros de viajes, cartas de amor nunca contestadas, figuras de papel recortado y alguna que otra pieza de teatro. Pero ante todo, nos legó sus cuentos, que seguiremos leyendo toda la vida, aunque nos provoquen esa etérea belleza o el mayor de los desgarros. Los leeremos siempre con ojos despiertos porque las hadas, los niños, usted y yo, señor Andersen, ya perdimos la inocencia.

Respetuosamente,

CR 


\section{REFERENCIAS}

Andersen, H. C. (1989). El cuento de mi vida. La Habana: Editorial Gente Nueva. Andersen, H. C. (1987). Cuentos de hadas para niños I. Madrid: Ediciones Gaviota. Andersen, H. C. (1985). Cuentos de hadas para niños II. Madrid: Ediciones Gaviota. Bettelheim, B. (1990). Psicoanálisis de los cuentos de hadas. Barcelona: Editorial Crítica.

Bonning, B. (1996), Prólogo. En Cajón de cuentos, Hans Ch. Andersen. Santafé de Bogotá: Editorial Panamericana, pp. 7-17.

Cashdan, S. (2000). La bruja debe morir. De qué modo influyen los cuentos de hadas en los niños. Madrid: Temas de debate.

Cubero, J. (1987), "Hans Christian Andersen". En Cuentos de hadas para niños I. Madrid: Ediciones Gaviota: 7-21.

Departamento de Información (1997). Hans Christian Andersen. Copenhague: Real Ministerio de Relaciones Exteriores de Dinamarca.

Edmée Álvarez, M. (1986), "La vida y los cuentos de Hans Christian Andersen". En Andersen, H. C. Cuentos. México D.F.: Editorial Porrúa, pp. IX-XXVIII.

Marín, A. (1992), "Introducción". En La Bella y la Bestia y otros cuentos. Barcelona: Ediciones Gaviota, pp. 5-15.

Montes, G. (2001). El corral de la infancia. México D.F.: Fondo de Cultura Económica.

Nobile, A. (1992). Literatura infantil y juvenil. Madrid: Ministerio de Educación y Ciencia y Ediciones Morata.

Pardo Belgrano, R. y Nervi, J. R. (1979). Lexicón de literatura infantil juvenil. Buenos Aires: Editorial Plus Ultra.

Pascual, E. (Noviembre, 1997). "Un cuentista en la Corte del rey Sol". En Cuadernos de Literatura Infantil y Juvenil (CLIJ), año 10, número 99, pp. 8-23.

Propp, V. (1987). Las raíces históricas del cuento. Madrid: Editorial Fundamentos.

Revista Informaciones Danesas, (1985). "Hans Christian Andersen", en Cuentos de hadas para niños II. Madrid: Ediciones Gaviota, pp. 7- 21.

Ruzicka Kenfel, V. (Noviembre, 1996). "Clásicos de la literatura universal". En Cuademos de Literatura Infantil y Juvenil (CLIJ), año 9, número 88, pp. 23-34.

Sandoval, C. (2003). Otros amenazantes. Los nicaragüenses y la formación de identidades nacionales en Costa Rica. San José: Editorial de la Universidad de Costa Rica.

Soriano, M. (1995). La literatura para niños y jóvenes. Guía de exploración de sus grandes temas. Buenos Aires: Editorial Colihue.

\section{Páginas consultadas en la Internet el 22 de marzo del 2005}

www.hca2005.com www.imaginaria.com.ar/lobreve/2000_11_01_archivo.htm www.geocities.com/cuatrogatos4/dossier.html 